\title{
New Treatments for Renal Cell Carcinoma: Targeted Therapies
}

\author{
Philip J. Saylor, MD, and M. Dror Michaelson, MD, PhD, Boston, Massachusetts
}

\section{Key Words}

Renal cell carcinoma, tyrosine kinase inhibitors, vascular endothelial growth factor, mammalian target of rapamycin, von Hippel-

Lindau, hypoxia inducible factor

\begin{abstract}
Systemic treatment options for advanced renal cell carcinoma (RCC) have expanded considerably with the development of targeted therapies. Clear cell RCC commonly features mutation or inactivation of the von Hippel-Lindau gene and resultant overexpression of vascular endothelial growth factor (VEGF). The first drug to validate VEGF as a target in the treatment of clear cell RCC was the monoclonal antibody bevacizumab. Since then, anti-VEGF receptor therapy with multitargeted kinase inhibitors also has shown substantial efficacy. Sunitinib is now a standard first-line therapy for advanced disease and sorafenib is among the second-line treatment options. Other kinase inhibitors are in development. Mammalian target of rapamycin (mTOR) is a second validated therapeutic target as the MTOR inhibitor temsirolimus has been shown to prolong survival in first-line treatment of poor prognosis RCC of all histologies. Everolimus is an oral mTOR inhibitor and has been shown to prolong progression-free survival when used in second-line treatment. Non-clear cell and sarcomatoid RCC are both underrepresented in completed trials but are the subject of active research. Ongoing and planned studies will also evaluate the use of combinations of targeted agents, a strategy that is not advisable outside of clinical trials. Finally, postnephrectomy adjuvant treatment with targeted agents is not yet standard but is under investigation in phase III trials. (JNCCN 2009;7:645-656)
\end{abstract}

From the Department of Oncology, Massachusetts General Hospital Cancer Center, Boston, Massachusetts.

Submitted February 4, 2009; accepted for publication

April 22, 2009.

Dr. Michaelson has disclosed that he has received honoraria from

Wyeth, Pfizer Inc., Abbott Laboratories, Genentech, Inc., and

Novartis. Dr. Saylor has no interest, arrangement, or affiliation

with the manufacturers of any products discussed in the article or

their competitors.

Correspondence: Philip J. Saylor, MD, Massachusetts General

Hospital, Lawrence House/POB: 2nd Floor, Boston, MA 02114.

E-mail: psaylor@partners.org
An estimated 54,390 people were diagnosed with cancer of the kidney or renal pelvis in the United States in 2008. ${ }^{1}$ At diagnosis, $19 \%$ had disease that had already spread regionally and 20\% had metastatic disease. Approximately 13,010 people with kidney and renal pelvic cancers died in the United States in 2008.

Systemic treatment options for patients who cannot be cured surgically have been limited until recent years. Renal cell carcinoma (RCC) has long been known to respond poorly to cytotoxic chemotherapy. ${ }^{2}$ Immunotherapy with cytokines, such as interferon- $\alpha$ or interleukin-2 (IL-2), has shown modest activity at the expense of substantial toxicity. ${ }^{3-6}$

This article will describe recent advances in the use of targeted therapies for advanced RCC and focus on agents that have been evaluated in published phase III and randomized phase II trials. Sorafenib, sunitinib, everolimus, and temsirolimus have all been FDA-approved to treat advanced RCC. Bevacizumab may soon be approved, and additional targeted agents are in clinical trials.

Although this article does not discuss cytokine therapy, it is important to note that high-dose IL-2 offers measurable complete response and durable remission rates in properly selected patients with advanced disease. ${ }^{7-9}$ High-dose IL-2 therapy, particularly for patients with a high Karnofsky performance status $(>80)$ and low-volume or lung-predominant metastatic disease, is a category $2 \mathrm{~A}$ recommendation by the NCCN Clinical Practice Guidelines in Oncology: Kidney Cancer Pane ${ }^{10}$ and should be discussed with patients who are appropriate for such consideration.

Cytoreductive nephrectomy before systemic therapy for advanced disease is recommended when feasible because it has been shown to improve survival. ${ }^{10}$ The trials that established this were conducted when systemic therapy was limited to cytokines. ${ }^{11-13}$ The role of 
nephrectomy before targeted therapy has not been evaluated in randomized trials.

\section{Molecular Background}

The study of von Hippel-Lindau (VHL) disease led to much of the current molecular understanding of sporadic RCC. VHL disease is an autosomal dominant syndrome characterized by benign and malignant tumors, such as hemangioblastomas and clear cell RCC. The usual VHL gene product, pVHL, is a tumor suppressor that, as one of its functions, targets several proteins for ubiquitination and proteasomal degradation in the presence of oxygen (see Figure 1). ${ }^{14}$ Patients with VHL disease harbor a germline mutation in one allele of the VHL gene. If the second allele is compromised, pVHL function is lost.

First discovered in VHL disease, VHL mutations were later found in many cases of sporadic clear cell RCC. ${ }^{15}$ Hypermethylation is a second but less common mechanism for VHL gene inactivation. ${ }^{16}$ In one series of 110 sporadic RCC tumors, VHL mutations were detected in $57 \% .{ }^{15}$ In a similar study $(\mathrm{n}=187)$, VHL mutations were detected in $52 \%$ and promoter hypermethylation in $5.3 \% .{ }^{17}$

As a consequence of VHL inactivation, clear cell RCC commonly features inappropriate stabilization and accumulation of hypoxia-inducible factor $\alpha$ transcription factors (HIF- $1 \alpha$ and $-2 \alpha$ ). ${ }^{18}$ Greater expression of HIF- $\alpha$ transcription factors is associated with increased vascular endothelial growth factor (VEGF) mRNA and protein and increased microvessel density. ${ }^{19,20}$ Recently, HIF- $\alpha$ expression analysis of 160 primary kidney tumors showed 2 distinct patterns among pVHL-deficient tumors: those that express HIF-2 $\alpha$ and those that express both HIF-1 $\alpha$ and $-2 \alpha .^{21}$ Those

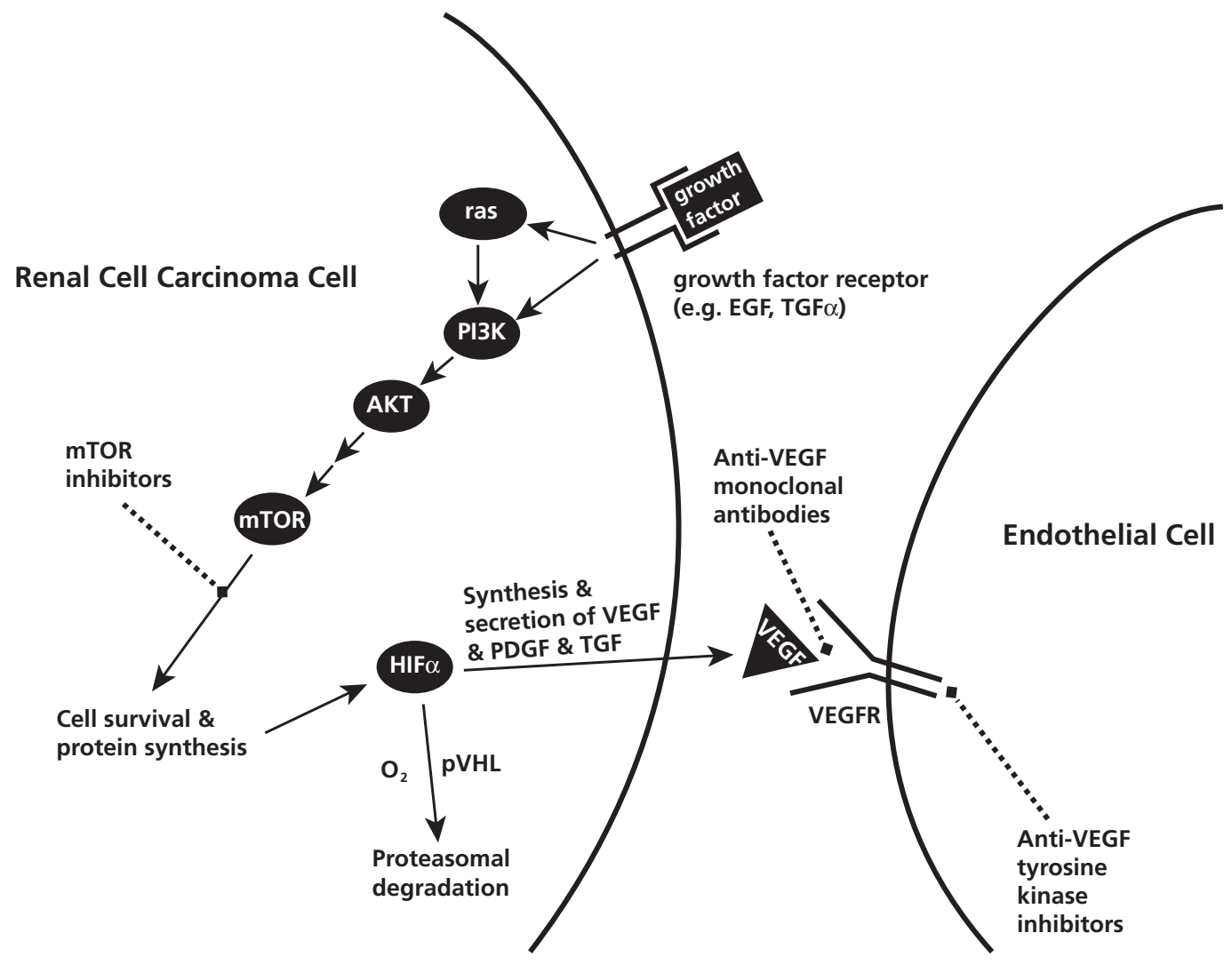

Figure 1 Simplified renal cell carcinoma pathways relevant to current targeted therapies.

Abbreviations: EGF, epidermal growth factor; HIF $\alpha$, hypoxia-inducible factor $\alpha$; mTOR, mammalian target of rapamycin; O2, oxygen; PDGF, platelet-derived growth factor; pVHL, von Hippel-Lindau protein; TGF $\alpha$, tumor growth factor $\alpha$; VEGF, vascular endothelial growth factor; VEGFR, vascular endothelial growth factor receptor.

Data from Courtney KD, Choueiri TK. Optimizing recent advances in metastatic renal cell carcinoma. Curr Oncol Rep 2009;11:218-226. 
that expressed only HIF-2 $\alpha$ displayed elevated c-Myc activity, arguing for a new molecular subclassification among clear cell tumors.

Clear cell-type renal tumors account for $65 \%$ to $88 \%$ of cases of RCC ${ }^{22,23}$ and have long been observed to be highly vascular. VHL mutations are present in most clear cell RCCs and cause excess downstream secretion of HIF-regulated proteins, such as VEGF. The prevalence of VHL mutations in clear cell RCC therefore led to the investigation of VEGF as a therapeutic target. The first agent to validate this target was bevacizumab, a humanized monoclonal antibody that binds circulating VEGF-A.

\section{Bevacizumab}

Bevacizumab was studied in a randomized phase II trial of 116 patients with metastatic RCC who had progressed on IL-2. ${ }^{6}$ Subjects were randomized to 1 of 3 treatment arms: bevacizumab $(10 \mathrm{mg} / \mathrm{kg}$ every 2 weeks), low-dose bevacizumab ( $3 \mathrm{mg} / \mathrm{kg}$ ), or placebo. The primary end points were time to progression (TTP) and response rate. Interim analysis met the early stopping rule because it showed improved TTP in the higher-dose group relative to placebo (hazard ratio [HR], 2.55; $P<.001)$.

The higher dose $(10 \mathrm{mg} / \mathrm{kg}$ every 2 weeks) was then combined with cytokine therapy in the first-line phase III AVOREN trial (Table 1). ${ }^{24}$ This trial randomized 649 patients with previously untreated metastatic clear cell-predominant RCC to interferon- $\alpha$ (typical dose: 9 MIU subcutaneously, 3 times weekly) with or without bevacizumab. Although the trial was designed to primarily evaluate overall survival, analysis was confounded by the interim development of alternate targeted agents that could be used secondline. The trial was therefore unblinded and progression-free survival became the primary end point. The experimental arm experienced improved progressionfree survival (10.2 vs. 5.4 months; $P=.0001)$, fewer progression events (230 vs. 275), and fewer deaths (114 vs. 137), and underwent treatment almost twice as long (9.7 vs. 5.1 months). Fatigue (12\%) and asthenia (10\%) were the most common grade 3 adverse events in the experimental arm (see Table 2).

The similarly-designed CALGB 90206 trial studied interferon- $\alpha$ with or without bevacizumab (10 $\mathrm{mg} / \mathrm{kg}$ every 2 weeks) for first-line treatment of metastatic clear cell RCC. ${ }^{25}$ It was powered to evalu- ate overall survival and enrolled 732 patients. Overall survival data are pending. The experimental arm experienced superior TTP (8.5 vs. 5.2 months; log rank, $P<.0001)$ and overall response rate $(25.5 \%$ vs. $13.1 \% ; P<.0001)$. The experimental arm experienced greater toxicities, most notably the following grade 3 side effects: hypertension ( $9 \%$ vs. $0 \%$ ), anorexia ( $17 \%$ vs. $8 \%)$, fatigue ( $35 \%$ vs. $28 \%)$, and proteinuria (13\% vs. 0\%).

Based on these trials, bevacizumab may soon gain FDA approval for the treatment of RCC. Current practice varies because some clinicians prescribe bevacizumab monotherapy, as used in the phase II National Cancer Institute study, whereas others prescribe the bevacizumab/interferon- $\alpha$ regimen used in both phase III trials. The relative contribution of interferon- $\alpha$ to the efficacy and toxicity of the combination is not defined because bevacizumab has never been compared with bevacizumab/interferon- $\alpha$ in a randomized trial.

\section{Tyrosine Kinase Inhibition}

\section{Sorafenib}

The efficacy of bevacizumab, a monoclonal antibody, established VEGF as a therapeutic target in RCC. Since then, most promising agents have been small molecule kinase inhibitors. Sorafenib, an oral inhibitor of VEGF receptors (VEGFR) 1 through 3, platelet-derived growth factor receptor (PDGFR) $\beta$, and B-Raf, ${ }^{26-30}$ was the first kinase inhibitor to show benefit in a phase III trial.

The phase III TARGET trial randomized 903 patients with metastatic clear cell RCC who experienced progression on cytokine therapy to oral sorafenib (400 mg, twice daily) or placebo. ${ }^{31} \mathrm{Al}$ though the trial had been designed to evaluate overall survival, planned interim analysis of progressionfree survival found the sorafenib arm to be superior (median progression-free survival, 5.5 vs. 2.8 months; HR for progression, $0.44 ; P<.01$ ). Crossover from placebo to sorafenib was then permitted, potentially confounding survival evaluation. HR for death was 0.72 in the sorafenib arm $(95 \% \mathrm{CI}, 0.54-0.94$; $P=.02$ ), although this was not significant according to the prespecified O'Brien-Fleming threshold for this interim analysis. The response rate to sorafenib was modest but superior to that with placebo $(10 \%$ vs. $2 \% ; P<.001)$. Sorafenib is now FDA-approved for the treatment of advanced RCC. 

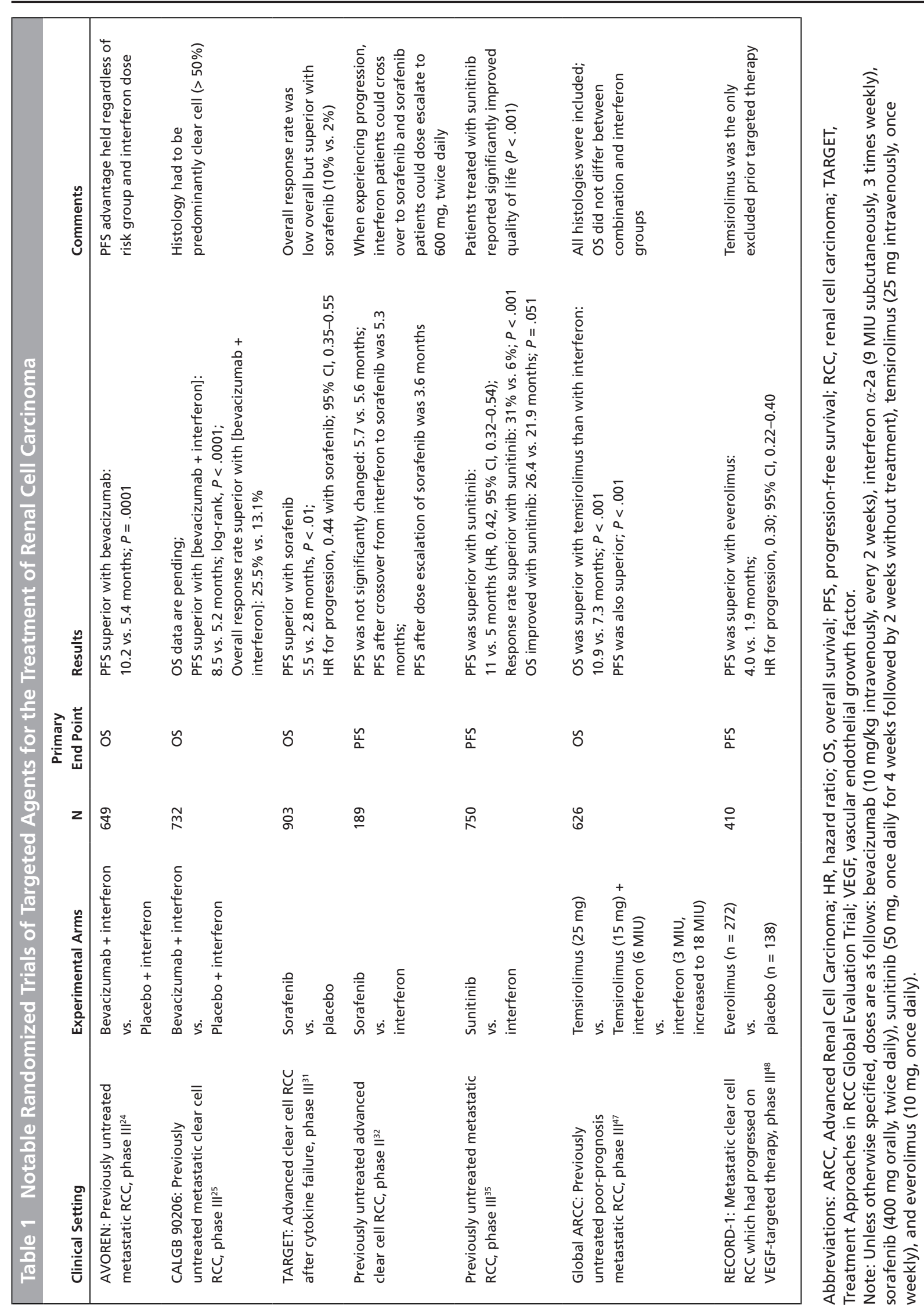


\begin{tabular}{|c|c|c|c|c|c|c|}
\hline & \multicolumn{6}{|c|}{ Drug } \\
\hline & $\begin{array}{l}\text { Bevacizumab } \\
+ \text { Interferon }\end{array}$ & Sorafenib & Sunitinib & Axitinib & Temsirolimus & Everolimus \\
\hline Trial & $\begin{array}{l}\text { Escudier et } \\
\text { al. }{ }^{24}\end{array}$ & $\begin{array}{l}\text { Escudier et } \\
\text { al. }{ }^{31}\end{array}$ & Motzer et al. ${ }^{35}$ & Rixe et al. ${ }^{45}$ & Hudes et al. ${ }^{47}$ & $\begin{array}{l}\text { Motzer et } \\
\text { al. }{ }^{48}\end{array}$ \\
\hline No. patients & 337 & 451 & 375 & 52 & 208 & 269 \\
\hline Mechanism & $\mathrm{mAb}$ & $\begin{array}{l}\text { kinase } \\
\text { inhibitor }\end{array}$ & TKI & TKI & $\begin{array}{l}\text { Allosteric } \\
\text { inhibitor of } \\
\text { mTOR kinase }\end{array}$ & $\begin{array}{l}\text { Allosteric } \\
\text { inhibitor of } \\
\text { mTOR kinase }\end{array}$ \\
\hline Drug target(s) & VEGF & $\begin{array}{l}\text { VEGFR-2, } \\
\text { FLT3, PDGFR, } \\
\text { FGFR1, C-raf, } \\
\text { B-Raf }\end{array}$ & $\begin{array}{l}\text { VEGFR, } \\
\text { PDGFR, c-kit }\end{array}$ & VEGFR-1, $-2,-3$ & mTOR & mTOR \\
\hline Fatigue & $12(33)$ & $5(37)$ & $7(51)$ & $8(54)$ & & $3(20)$ \\
\hline Hypertension & $3(26)$ & $4(17)$ & $8(24)$ & $15(60)$ & & \\
\hline Diarrhea & $2(20)$ & $2(43)$ & $5(53)$ & $10(62)$ & $1(27)$ & $1(17)$ \\
\hline $\begin{array}{l}\text { Hand/foot skin } \\
\text { reaction }\end{array}$ & & $6(30)$ & $5(20)$ & & & \\
\hline Pain & & $\begin{array}{l}2(11) \\
\text { abdomen; } \\
1(8) \text { bone; } \\
2 \text { (10) joint; } \\
3 \text { (6) tumor }\end{array}$ & $\begin{array}{l}1 \text { (11) limb; } \\
1 \text { (5) myalgia }\end{array}$ & $\begin{array}{l}0 \text { (12) abdomen; } \\
0 \text { (14) arthralgia; } \\
4 \text { (20) limb; } \\
2 \text { (12) myalgia }\end{array}$ & $\begin{array}{l}4(21) \\
\text { abdomen; } \\
5(28) \text { any; } \\
3(20) \text { back }\end{array}$ & \\
\hline Asthenia & $10(32)$ & & $4(17)$ & & $11(51)$ & $1(18)$ \\
\hline Dyspnea & < $1(13)$ & $4(14)$ & & & $9(28)$ & $1(8)$ \\
\hline Infection & & & & & $5(27)$ & $3(10)$ \\
\hline Anemia & $3(10)$ & $3(8)$ & $4(71)$ & & $20(45)$ & $9(91)$ \\
\hline Leukopenia & & & $5(78)$ & & $1(6)$ & $0(26)$ \\
\hline Neutropenia & $4(7)$ & $5(18)$ & $12(72)$ & & $3(7)$ & $0(11)$ \\
\hline Lymphopenia & & 13 & $12(60)$ & & & $15(42)$ \\
\hline Elevated uric acid & & & $12(41)$ & & & \\
\hline Elevated lipase & & $12(41)$ & $16(52)$ & & & \\
\hline Elevated amylase & & & $5(32)$ & & & \\
\hline Hyperglycemia & & & & & $11(26)$ & $12(50)$ \\
\hline Thrombocytopenia & $2(6)$ & $1(12)$ & $8(65)$ & & $1(14)$ & $<1(20)$ \\
\hline Proteinuria & $7(18)$ & & & & & \\
\hline Hypophosphatemia & & 13 & $5(36)$ & & & $4(32)$ \\
\hline ALT Elevation & & & & & & \\
\hline
\end{tabular}

Abbreviations: mAb, monoclonal antibody; FGFR1, fibroblast growth factor receptor-1; mTOR, mammalian target of rapamycin; PDGFR, platelet-derived growth factor receptor; TKI, small molecule tyrosine kinase inhibitor; VEGF, vascular endothelial growth factor; VEGFR, vascular endothelial growth factor receptor.

${ }^{*}$ All dosing is typical.

tListed are all toxicities that are experienced as higher than grade 3 by at least $5 \%$ of patients in any of the cited trials. Numbers are expressed as the percentage of patients experiencing grade 3 to 4 toxicity (percentage experiencing any-grade toxicity in parentheses). 
The most prominent adverse events with sorafenib were diarrhea, rash, fatigue, and hand-foot skin reactions (Table 2). Rare hypertension, cardiac ischemia, and acute coronary syndromes were also noted. The incidence of cardiac ischemia/infarction was $2.9 \%$ with sorafenib and $0.4 \%$ with placebo.

A phase II trial that tested sorafenib as firstline therapy for metastatic $\mathrm{RCC}^{32}$ randomized 189 patients with advanced RCC to either sorafenib (400 mg, twice daily) or interferon- $\alpha$. The study did not meet its primary end point because progression-free survival was similar in the sorafenib and interferon- $\alpha$ groups (5.7 vs. 5.6 months, respectively). The response rate was less than $10 \%$ in both arms. Rash and diarrhea were more common with sorafenib, whereas flu-like symptoms were more common with interferon- $\alpha$. Based on this trial, firstline sorafenib at standard doses seems to offer no advantage over first-line cytokine therapy.

\section{Sunitinib}

The current first-line standard of care for patients with good- or intermediate-risk advanced clear cell RCC is sunitinib, a drug that inhibits PDGFR- $\alpha$ and $-\beta$, VEGFRs -1 through -3 , stem cell factor receptor (c-KIT), FMS-like tyrosine kinase, colony-stimulating factor, and neurotrophic factor receptor.

After showing unprecedented activity in single arm trials, ${ }^{33,34}$ sunitinib was compared with interferon- $\alpha$ as first-line treatment of advanced clear cell RCC in a phase III trial. ${ }^{35}$ This trial randomized 750 patients to either interferon- $\alpha$ or sunitinib (50 mg orally, once daily for 4 weeks followed by 2 weeks rest). The groups were well balanced because each had fewer than $10 \%$ of patients with poor-risk disease by Memorial Sloan-Kettering Cancer Center (MSKCC) criteria. ${ }^{36}$ The primary end point, median progressionfree survival, was improved in the sunitinib arm (11 vs. 5 months; HR for progression, $0.42 ; P<.001$ ), as was objective response rate ( $31 \%$ vs. $6 \%)$.

Grade 3 or higher treatment-related fatigue was more common with interferon- $\alpha$, although diarrhea was more common with sunitinib (Table 2). Treatment-related quality of life, assessed by 2 validated questionnaires (FACT-G [Functional Assessment of Cancer Therapy: General], FKSI [Functional Assessment of Cancer Treatment: Kidney Index]), was better in the sunitinib group $(P<.001)$. Mature data have since been presented and suggest improved overall survival in the sunitinib arm (26.4 vs. 21.8 months; $P=.051) .37$ This trial provides evidence supporting sunitinib as first-line therapy for goodand intermediate-risk advanced clear cell RCC. Sunitinib is FDA-approved.

\section{Toxicities}

Common side effects of VEGF-targeted therapies for RCC include fatigue, hypertension, diarrhea, skin toxicity, and others (Table 2). Three toxicities that deserve specific mention are hypothyroidism, cardiac toxicity, and hand-foot skin toxicity.

Fatigue is a prominent side effect of sunitinib, with an incidence of more than $50 \% .{ }^{35}$ Hypothyroidism is sometimes the underlying cause. In one series, 66 patients treated with sunitinib had also been evaluated with thyroid function tests. ${ }^{38}$ Of those 66 subjects, $56(85 \%)$ had at least 1 thyroid function laboratory abnormality, most commonly elevated thyroid-stimulating hormone with low T3. In that series, all laboratory abnormalities normalized with thyroid hormone supplementation. Although routine monitoring of thyroid function is rational, no standard of care has been defined. Clinical monitoring throughout treatment is appropriate.

Cardiotoxicity has been thoroughly studied with sunitinib treatment. In a retrospective review of 75 patients treated with sunitinib, a composite of cardiovascular events (cardiac death, myocardial infarction, and congestive heart failure) occurred in $8(11 \%) .{ }^{39}$ Two sunitinib trials prospectively examined left ventricular ejection fraction (LVEF). In one, the incidence of grade 3 decline after 6 months was similar in the sunitinib and interferon- $\alpha$ arms ( $2 \%$ vs. $1 \%)$. All declines were reversible with discontinuation or dose reduction. ${ }^{35}$ In another trial $(\mathrm{n}=207)$, LVEF measured at baseline and day 28 of each treatment cycle did not show a decrease. ${ }^{40}$ Outside of trials, it is reasonable to obtain a baseline echocardiogram in patients at risk for congestive heart failure and to clinically monitor all patients for related signs and symptoms.

Tenderness/pain, erythema, blistering, and scaling of the finger tips, palms, and soles have been commonly observed with sorafenib and sunitinib and can substantially affect quality of life. This toxicity may develop within the first 2 to 4 weeks of therapy ${ }^{41}$ and particularly affects points of weight-bearing or flexure. Its reported incidence has ranged from $9 \%$ to as high as $62 \% .{ }^{42}$ The incidence of grade 3 toxicity is $5 \%$ to $6 \% .^{31,35}$ Evidence-based recommendations 
Targeted Therapies for Renal Cell Carcinoma

for managing this toxicity are absent. Dose reduction or temporary stoppage is often advisable. Careful choice of footwear and avoidance of excessive friction or hot water can be preventative measures. ${ }^{42}$ Moisturizers and keratolytics (e.g., 20\%-40\% urea cream) are reasonable. Topical steroids and analgesics can be considered in more severe cases.

\section{Pazopanib}

Pazopanib is an experimental kinase inhibitor that targets VEGFR-1 to -3 , PDGFR- $\alpha$ and $-\beta$, and c-Kit. Daily oral pazopanib was evaluated in a randomized, placebo-controlled phase II trial ${ }^{43}$ that enrolled patients with advanced RCC that was treatment naivve $(67 \%)$ or refractory to one prior cytokine and/or bevacizumab-containing regimen (33\%). Analysis of the first 60 patients treated with pazopanib showed a partial response rate of $40 \%(n=24)$ and stable disease of $42 \%(n=25)$. The rate of grade 3 or 4 adverse events was $26 \%$, with the most prominent being hypertension ( $8 \%)$ and alanine aminotransferase elevation (8\%). Common lower-grade toxicities included diarrhea, fatigue, nausea, and hair depigmentation. Updated 12-week response rate $(\mathrm{n}=225)$ was later reported to be a more modest $27 \%{ }^{44}$

Pazopanib is now being studied in 2 randomized phase III trials (Table 3). The first is testing it against placebo for the second-line treatment of advanced clear cell RCC after cytokine failure, whereas the second is comparing it with sunitinib for the first-line treatment of advanced clear cell RCC. Pazopanib is not FDA-approved.

\section{Axitinib}

Axitinib is a selective oral inhibitor of VEGFR-1 through - 3. It was studied in a single-arm phase II trial for patients with metastatic cytokine-refractory disease $(n=52) .{ }^{45}$ The response rate was $44.2 \%$ ( 2 complete responses, 21 partial responses). Median TTP and overall survival were 15.7 and 29.9 months, respectively. Adverse events included diarrhea, fatigue, hypertension, nausea, and hoarseness. The rate of treatment-related hypertension was $58 \%(\mathrm{n}=30)$, although most cases were controlled with antihypertensives. Subsequent studies have correlated treatmentrelated hypertension with efficacy, and a planned phase II trial will titrate the dose to development of hypertension. A phase III trial of second-line therapy for metastatic disease is comparing axitinib with sorafenib (Table 3). Axitinib is not FDA approved.

\section{Mammalian Target of Rapamycin Inhibition}

\section{Temsirolimus}

Mammalian target of rapamycin (mTOR) kinase is thought to be important to cellular growth and proliferation because it mediates a growth factor receptor pathway downstream of phosphatidyl inositol 3-kinase and AKT. ${ }^{46}$ It has become a validated target for the treatment of RCC, with 2 rapamycin derivatives (temsirolimus, everolimus) gaining FDA approval. Both rapamycin analogs are competitive inhibitors of mTOR kinase.

Temsirolimus, a specific inhibitor of mTOR, was evaluated in the phase III Advanced Renal Cell Carcinoma (ARCC) trial, ${ }^{47}$ involving 626 patients with poor-prognosis, previously untreated metastatic RCC of various histologic types. The definition of poor prognosis in this trial was a modified version of the widely used MSKCC criteria. MSKCC defines poor-risk patients as having 3 or more of the following 5 pretreatment features: low Karnofsky performance status, high lactate dehydrogenase, low hemoglobin, high corrected serum calcium, and less than 1 year from diagnosis to the start of therapy. ${ }^{36}$ The ARCC trial added a sixth risk factor: metastases in multiple organs. Because multiple organs were involved in $80 \%$ of the enrolled patients, some patients met poor-risk criteria only according to this modified definition.

Patients were randomized among 3 arms: interferon- $\alpha$ monotherapy, combination therapy using interferon- $\alpha$ and $15 \mathrm{mg}$ weekly temsirolimus, or monotherapy with $25 \mathrm{mg}$ of weekly temsirolimus. The primary end point was survival. Overall survival (HR for death, 0.73; $P=.008$ ) and progressionfree survival $(P<.001)$ were improved with temsirolimus alone compared with interferon- $\alpha$ alone. No survival benefit was seen in the combination arm compared with the interferon arm. Median overall survival was 10.9 months with temsirolimus, 8.4 months with combination therapy, and 7.3 months with interferon- $\alpha$. The most common adverse effects of temsirolimus were rash, peripheral edema, hyperglycemia, and hyperlipidemia (see Table 2). Based on this study, temsirolimus was FDA-approved for treating advanced RCC and is an appropriate first-line treatment for poor-prognosis RCC of any histology. 


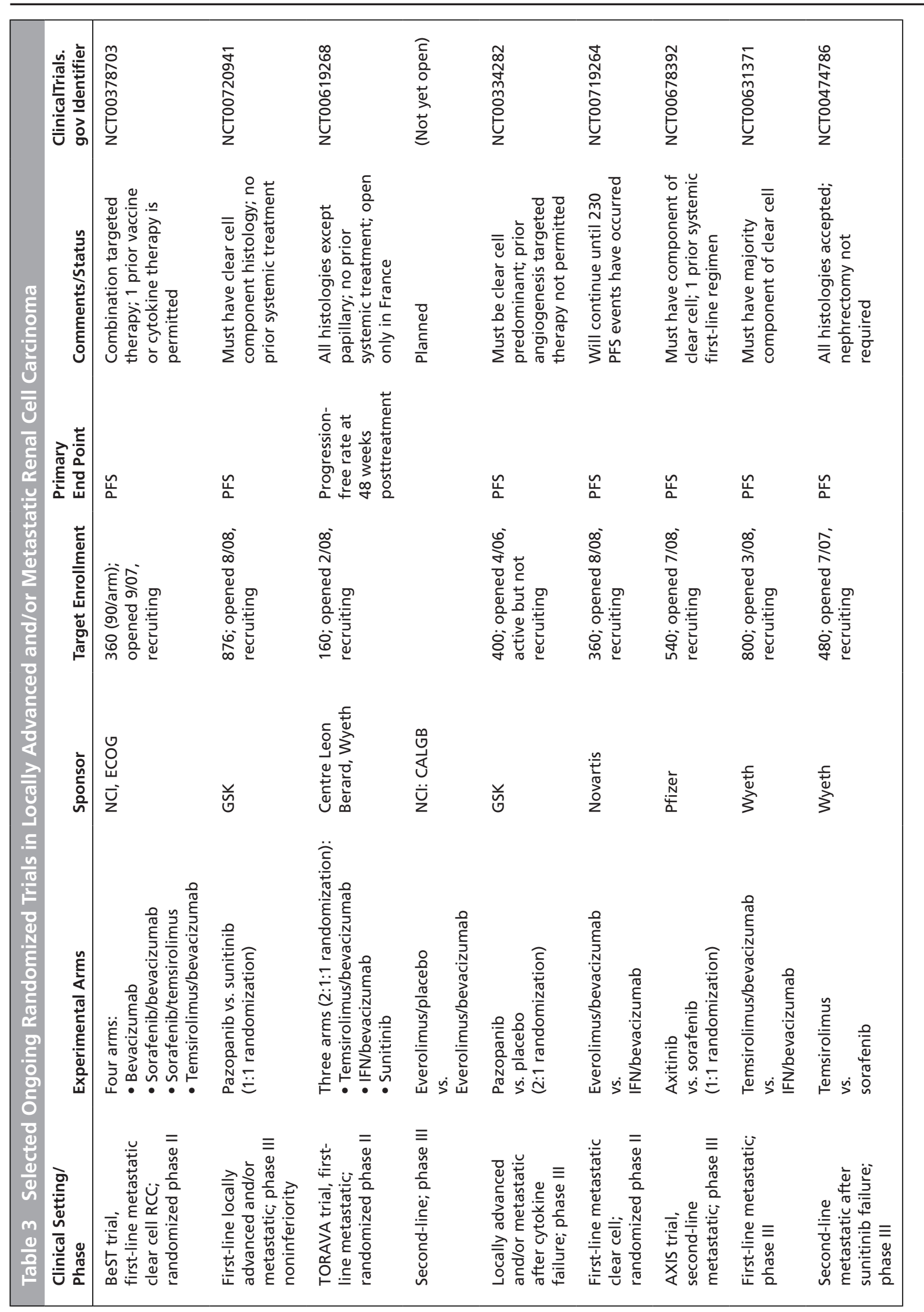

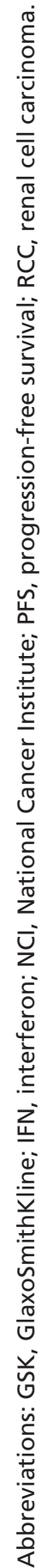




\section{Everolimus}

Everolimus is an oral mTOR inhibitor that is mechanistically similar to temsirolimus. Activity in an early-phase study led to a phase III trial for metastatic clear cell RCC that progressed on VEGF-targeted therapy ${ }^{48}$ Subjects were randomized 2:1 to everolimus (10 mg, daily) or placebo, with progression-free survival the primary end point. The second interim analysis after 191 progression events showed superior results in the everolimus arm, and the study was halted. Progression-free survival (HR, 0.30; $P<.0001$; median progression-free survival, 4.0 vs. 1.9 months) was improved with everolimus. Common toxicities are detailed in Table 2. Significant side effects included stomatitis (40\%), rash (25\%), and fatigue (20\%). Notably, $8 \%$ of everolimus patients experienced pneumonitis, with approximately a third grade 3 .

Based on its modest but clearly observed progression-free survival benefit, everolimus is a reasonable choice for second-line therapy and has gained FDA approval.

\section{Epidermal Growth Factor Receptor Targeted Therapy}

Epidermal growth factor receptor (EGFR) is overexpressed in most RCC cases and associated with the presence of metastases. ${ }^{49}$ Tumor blood vessels also commonly stain positive for its ligand, transforming growth factor- $\alpha .{ }^{49}$ Although EGFR-targeted therapy is a rational approach for RCC and has shown promise in preclinical study, ${ }^{50}$ it has thus far been clinically unsuccessful. One example is lapatinib, a tyrosine kinase inhibitor of EGFR and human epidermal growth factor receptor 2 (HER-2). A phase III trial for advanced RCC $(n=416)$ that compared lapatinib, $1250 \mathrm{mg}$ daily, with hormone therapy (tamoxifen or megestrol acetate $)^{51}$ showed that TTP did not differ between arms (15.3 vs. 15.4 weeks). Among patients with EGFR overexpression according to immunohistochemistry $(\mathrm{n}=241)$, TTP was marginally improved (15.1 vs. 10.9 weeks; $\mathrm{HR}, 0.76 ; P=.06$ ).

\section{Non-Clear Cell RCC}

Treatment options for non-clear cell RCC are not yet well defined. Non-clear cell histologies represent $15 \%$ to $20 \%$ of all RCC. ${ }^{52}$ Papillary RCC accounts for approximately $80 \%$ of these and is followed by chromophobe, collecting duct, unclassified, and medullary carcinomas.

The rationale for VEGF-targeted treatment for non-clear cell RCC is uncertain. In theory, VEGF inhibition is used to counteract the effects of the VHL gene inactivation commonly seen only in clear cell RCC. Small retrospective analyses of non-clear cell RCC treated with sunitinib or sorafenib have reported low response rates. ${ }^{53,54}$ Most of the previously mentioned clinical trials have limited enrollment to clear cell RCC. The phase III trial of temsirolimus is a notable exception, as 124 of 626 patients (19.8\%) had non-clear cell disease. ${ }^{47}$ When temsirolimus $(\mathrm{n}=37)$ was compared with interferon- $\alpha(\mathrm{n}=36)$ in that subset, overall survival (11.6 vs. 4.3 months) and progression-free survival ( 7.0 vs. 1.8 months) were strikingly better with temsirolimus. ${ }^{55}$

The study of hereditary papillary renal carcinoma (HPRC) has led to molecular insights about papillary RCC. HPRC is caused by a germline mutation in the tyrosine kinase domain of the c-MET protooncogene and associated with multifocal papillary RCC. ${ }^{56}$ Some sporadic papillary RCC also features activating MET mutations, with one series showing this in 17 of $129(13 \%)$ patients. ${ }^{57}$ MET inhibitors are in development and can be considered for patients with papillary renal carcinomas that harbor MET mutations. One open phase II study uses a c-MET kinase inhibitor (GSK1363089; formerly XL880).

Although temsirolimus and VEGF-targeted therapies both have low objective response rates in non-clear cell RCC, temsirolimus was shown to confer an overall survival benefit in the phase III ARCC trial. Given these data, temsirolimus is a reasonable first-line treatment for patients with advanced nonclear cell RCC. Prospective trials of other targeted therapies are needed for this subset of patients.

\section{Sarcomatoid RCC}

The spindle-shaped cells characteristic of sarcomatoid differentiation can be a feature of any common subtype of RCC (clear cell, papillary, chromophobe) and are found in $1 \%$ to $8 \%$ of cases overall. ${ }^{58}$ Sarcomatoid differentiation is associated with aggressive tumor biology, early metastasis, and poor prognosis. ${ }^{59-61}$ One retrospective review suggested that responses to VEGF-targeted therapy were limited to those with clear cell histology and fewer than 
20\% sarcomatoid elements. ${ }^{62}$ Although sarcomatoid $\mathrm{RCC}$ is more responsive to cytotoxic chemotherapy than other subtypes of RCC, ${ }^{63-65}$ response rates are modest. The combination of doxorubicin and gemcitabine is currently in a phase II cooperative group study. Two current phase II trials are examining the combination of cytotoxic chemotherapy with targeted therapy in the form of sunitinib/gemcitabine and capecitabine/gemcitabine/bevacizumab.

\section{Integration of Existing Targeted Therapies}

Because evidence-based integration of targeted therapies for RCC is in its infancy, clinical trial participation is always encouraged. Recently completed clinical trials using targeted therapies have not directly compared them with each other. Nonetheless, some conclusions can be made.

Sunitinib is the standard first-line agent for most patients with advanced clear cell RCC based on its clear progression-free survival benefit. ${ }^{35}$ Temsirolimus prolongs survival in poor-risk disease of any histology and can reasonably be used as first-line therapy for patients who have clear cell RCC with 3 or more risk factors according to the modified criteria used in that trial, ${ }^{47}$ or those who have non-clear cell RCC. Sunitinib and sorafenib are both reasonable first-line choices for non-clear cell RCC but are supported by a lower level of evidence than temsirolimus.

After patients experience progression on firstline therapy, everolimus and sorafenib improve progression-free survival. Sunitinib and temsirolimus are also reasonable choices when they have not already been used in the first-line setting. The choice of second-line therapy can reasonably be shaped by an effort to use an agent that is mechanistically distinct from the first-line agent, although no data are available for this practice.

Bevacizumab/interferon- $\alpha$ combination is a reasonable choice for first-line treatment of clear cell RCC, but application of the clinical trial data has 2 limitations. First, the phase III trials have enrolled only previously untreated patients, and second, interferon- $\alpha$ contributes to side effects but is of uncertain added value. Bevacizumab monotherapy is a reasonable strategy but has only been tested in a phase II study.

\section{Future Directions}

\section{Combination Therapy}

Targeted agents generally have not been combined in completed trials. This is beginning to change; combination therapy is currently under investigation in several notable trials (Table 3). Among the combinations are sorafenib/bevacizumab, sorafenib/ temsirolimus, temsirolimus/bevacizumab, and everolimus/bevacizumab.

In the second-line setting, whether the first-line treatment should be replaced or added to is not yet clear. These issues can only be answered by prospective trials. No combination of targeted therapies should be used outside of clinical trials.

\section{Adjuvant Therapy}

Current standard care for fully resected RCC is observation, regardless of relapse risk. Given the efficacy of targeted therapy in the advanced setting, investigators are studying systemic treatment for preventing relapse after surgery for localized RCC. Adjuvant sunitinib and sorafenib are being compared in a 3-arm, randomized, placebo-controlled trial for intermediate- and high-risk RCC after nephrectomy. The trial is powered to examine disease-free survival and was designed to enroll 1332 patients. Enrollment has completed in another placebo-controlled phase III adjuvant trial using cG250, a monoclonal antibody to the MN surface antigen present in clear cell cancer. These and future studies may identify a role for targeted therapy in not only treating advanced RCC, but also preventing relapse after localized therapy.

\section{References}

1. Surveillance, Epidemiology and End Results (SEER). SEER Stat Fact Sheets: Kidney and Renal Pelvis. Available at: http://seer. cancer.gov/statfacts/html/kidrp.html. Accessed April 23, 2009.

2. Yagoda A, Petrylak D, Thompson S. Cytotoxic chemotherapy for advanced renal cell carcinoma. Urol Clin North Am 1993;20:303321.

3. Atkins $M B$, Regan $M$, McDermott D. Update on the role of interleukin 2 and other cytokines in the treatment of patients with stage IV renal carcinoma. Clin Cancer Res 2004;10(18 Pt 2):6342S-6346S.

4. McDermott DF, Regan MM, Clark JI, et al. Randomized phase III trial of high-dose interleukin-2 versus subcutaneous interleukin-2 and interferon in patients with metastatic renal cell carcinoma. J Clin Oncol 2005;23:133-141.

5. Motzer RJ, Russo P. Systemic therapy for renal cell carcinoma. J Urol 2000;163:408-417. 
Targeted Therapies for Renal Cell Carcinoma

6. Yang JC, Haworth L, Sherry RM, et al. A randomized trial of bevacizumab, an anti-vascular endothelial growth factor antibody, for metastatic renal cancer. N Engl J Med 2003;349:427-434.

7. Yang JC, Sherry RM, Steinberg SM, et al. Randomized study of high-dose and low-dose interleukin-2 in patients with metastatic renal cancer. J Clin Oncol 2003;21:3127-3132.

8. Negrier S, Escudier B, Lasset C, et al. Recombinant human interleukin-2, recombinant human interferon alfa-2a, or both in metastatic renal-cell carcinoma. Groupe Francais d'Immunotherapie. N Engl J Med 1998;338:1272-1278.

9. Fyfe GA, Fisher RI, Rosenberg SA, et al. Long-term response data for 255 patients with metastatic renal cell carcinoma treated with high-dose recombinant interleukin-2 therapy. J Clin Oncol 1996;14:2410-2411.

10. Motzer RJ, Agarwal N, Beard C, et al. NCCN Clinical Practice Guidelines in Oncology: Kidney Cancer. Version 2, 2009. Available at: http://www.nccn.org/professionals/physician_gls/PDF/kidney. pdf. Accessed April 23, 2009.

11. Flanigan RC, Mickisch G, Sylvester R, et al. Cytoreductive nephrectomy in patients with metastatic renal cancer: a combined analysis. J Urol 2004;171:1071-1076.

12. Flanigan RC, Salmon SE, Blumenstein BA, et al. Nephrectomy followed by interferon alfa-2b compared with interferon alfa- $2 b$ alone for metastatic renal-cell cancer. N Engl J Med 2001;345:16551659.

13. Mickisch GH, Garin A, van Poppel H, et al. Radical nephrectomy plus interferon-alfa-based immunotherapy compared with interferon alfa alone in metastatic renal-cell carcinoma: a randomised trial. Lancet 2001;358:966-970.

14. Iliopoulos $\mathrm{O}$, Levy AP, Jiang $\mathrm{C}$, et al. Negative regulation of hypoxia-inducible genes by the von Hippel-Lindau protein. Proc Natl Acad Sci U S A 1996;93:10595-10599.

15. Gnarra JR, Tory K, Weng Y, et al. Mutations of the VHL tumour suppressor gene in renal carcinoma. Nat Genet 1994;7:85-90.

16. Herman JG, Latif F, Weng Y, et al. Silencing of the VHL tumorsuppressor gene by DNA methylation in renal carcinoma. Proc Natl Acad Sci U S A 1994;91:9700-9704.

17. Yao M, Yoshida M, Kishida T, et al. VHL tumor suppressor gene alterations associated with good prognosis in sporadic clear-cell renal carcinoma. J Natl Cancer Inst 2002;94:1569-1575.

18. Maxwell PH, Wiesener MS, Chang GW, et al. The tumour suppressor protein VHL targets hypoxia-inducible factors for oxygen-dependent proteolysis. Nature 1999;399:271-275.

19. Turner KJ, Moore JW, Jones A, et al. Expression of hypoxiainducible factors in human renal cancer: relationship to angiogenesis and to the von Hippel-Lindau gene mutation. Cancer Res 2002;62:2957-2961.

20. Gnarra JR, Zhou S, Merrill MJ, et al. Post-transcriptional regulation of vascular endothelial growth factor mRNA by the product of the VHL tumor suppressor gene. Proc Natl Acad Sci U S A 1996;93:10589-10594.

21. Gordan JD, Lal P, Dondeti VR, et al. HIF-alpha effects on c-Myc distinguish two subtypes of sporadic VHL-deficient clear cell renal carcinoma. Cancer Cell 2008;14:435-446.

22. Patard JJ, Leray E, Rioux-Leclercq N, et al. Prognostic value of histologic subtypes in renal cell carcinoma: a multicenter experience. J Clin Oncol 2005;23:2763-2771.

23. Storkel S, van den Berg E. Morphological classification of renal cancer. World J Urol 1995;13:153-158.
24. Escudier B, Pluzanska A, Koralewski P, et al. Bevacizumab plus interferon alfa-2a for treatment of metastatic renal cell carcinoma: a randomised, double-blind phase III trial. Lancet 2007;370:21032111.

25. Rini BI, Halabi S, Rosenberg JE, et al. CALGB 90206: a phase III trial of bevacizumab plus interferon-alpha versus interferonalpha monotherapy in metastatic renal cell carcinoma [abstract]. Presented at the American Society of Clinical Oncology 2008 Genitourinary Cancers Symposium; February 14-16, 2008; San Francisco, California. Abstract 350.

26. Awada A, Hendlisz A, Gil T, et al. Phase I safety and pharmacokinetics of BAY 43-9006 administered for 21 days on/7 days off in patients with advanced, refractory solid tumours. Br J Cancer 2005;92:1855-1861.

27. Clark JW, Eder JP, Ryan D, et al. Safety and pharmacokinetics of the dual action Raf kinase and vascular endothelial growth factor receptor inhibitor, BAY 43-9006, in patients with advanced, refractory solid tumors. Clin Cancer Res 2005;11:5472-5480.

28. Moore M, Hirte HW, Siu L, et al. Phase I study to determine the safety and pharmacokinetics of the novel Raf kinase and VEGFR inhibitor BAY 43-9006, administered for 28 days on/7 days off in patients with advanced, refractory solid tumors. Ann Oncol 2005;16:1688-1694.

29. Strumberg D, Richly H, Hilger RA, et al. Phase I clinical and pharmacokinetic study of the novel Raf kinase and vascular endothelial growth factor receptor inhibitor BAY 43-9006 in patients with advanced refractory solid tumors. J Clin Oncol 2005;23:965-972.

30. Wilhelm SM, Carter C, Tang L, et al. BAY 43-9006 exhibits broad spectrum oral antitumor activity and targets the RAF/MEK/ ERK pathway and receptor tyrosine kinases involved in tumor progression and angiogenesis. Cancer Res 2004;64:7099-7109.

31. Escudier B, Eisen T, Stadler WM, et al. Sorafenib in advanced clear-cell renal-cell carcinoma. N Engl J Med 2007;356:125-134.

32. Szczylik C, Demkow T, Staehler M, et al. Randomized phase II trial of first-line treatment with sorafenib versus interferon in patients with advanced renal cell carcinoma: final results [abstract]. J Clin Oncol 2007;25(Suppl 1):Abstract 5025.

33. Motzer RJ, Michaelson MD, Redman BG, et al. Activity of SU11248, a multitargeted inhibitor of vascular endothelial growth factor receptor and platelet-derived growth factor receptor, in patients with metastatic renal cell carcinoma. J Clin Oncol 2006;24:16-24.

34. Motzer RJ, Rini BI, Bukowski RM, et al. Sunitinib in patients with metastatic renal cell carcinoma. JAMA 2006;295:2516-2524.

35. Motzer RJ, Hutson TE, Tomczak P, et al. Sunitinib versus interferon alfa in metastatic renal-cell carcinoma. $\mathrm{N}$ Engl J Med 2007;356:115-124.

36. Motzer RJ, Bacik J, Murphy BA, et al. Interferon-alfa as a comparative treatment for clinical trials of new therapies against advanced renal cell carcinoma. J Clin Oncol 2002;20:289-296.

37. Figlin R, Hutson TE, Tomczak P, et al. Overall survival with sunitinib versus interferon (IFN)-alfa as first-line treatment of metastatic renal cell carcinoma (mRCC) [abstract]. J Clin Oncol 2008;26(Suppl 1):Abstract 5024.

38. Rini BI, Tamaskar I, Shaheen P, et al. Hypothyroidism in patients with metastatic renal cell carcinoma treated with sunitinib. J Natl Cancer Inst 2007;99:81-83.

39. Chu TF, Rupnick MA, Kerkela R, et al. Cardiotoxicity associated with tyrosine kinase inhibitor sunitinib. Lancet 2007;370:20112019. 
40. Demetri GD, van Oosterom AT, Garrett CR, et al. Efficacy and safety of sunitinib in patients with advanced gastrointestinal stromal tumour after failure of imatinib: a randomised controlled trial. Lancet 2006;368:1329-1338.

41. Porta C, Paglino C, Imarisio I, Bonomi L. Uncovering Pandora's vase: the growing problem of new toxicities from novel anticancer agents. The case of sorafenib and sunitinib. Clin Exp Med 2007;7:127-134

42. Lacouture ME, Wu S, Robert C, et al. Evolving strategies for the management of hand-foot skin reaction associated with the multitargeted kinase inhibitors sorafenib and sunitinib. Oncologist 2008;13:1001-1011

43. Hutson TE, Davis ID, Machiels JP, et al. Pazopanib (GW786034) is active in metastatic renal cell carcinoma (RCC): interim results of a phase II randomized discontinuation trial (RDT) [abstract]. J Clin Oncol 2007;25(Suppl 1):Abstract 5031.

44. Hutson TE, Davis ID, Machiels JP, et al. Biomarker analysis and final efficacy and safety results of a phase II renal cell carcinoma trial with pazopanib (GW786034), a multi-kinase angiogenesis inhibitor [abstract]. J Clin Oncol 2008;26(Suppl 1):Abstract 5046.

45. Rixe O, Bukowski RM, Michaelson MD, et al. Axitinib treatment in patients with cytokine-refractory metastatic renal-cell cancer: a phase II study. Lancet Oncol 2007;8:975-984.

46. Schmelzle T, Hall MN. TOR, a central controller of cell growth. Cell 2000;103:253-262.

47. Hudes G, Carducci M, Tomczak P, et al. Temsirolimus, interferon alfa, or both for advanced renal-cell carcinoma. N Engl J Med 2007;356:2271-2281.

48. Motzer RJ, Escudier B, Oudard S, et al. Efficacy of everolimus in advanced renal cell carcinoma: a double-blind, randomised, placebo-controlled phase III trial. Lancet 2008;372:449-456.

49. Uhlman DL, Nguyen P, Manivel JC, et al. Epidermal growth factor receptor and transforming growth factor alpha expression in papillary and nonpapillary renal cell carcinoma: correlation with metastatic behavior and prognosis. Clin Cancer Res 1995;1:913920.

50. Prewett M, Rothman M, Waksal H, et al. Mouse-human chimeric anti-epidermal growth factor receptor antibody C225 inhibits the growth of human renal cell carcinoma xenografts in nude mice. Clin Cancer Res 1998;4:2957-2966.

51. Ravaud A, Hawkins R, Gardner JP, et al. Lapatinib versus hormone therapy in patients with advanced renal cell carcinoma: a randomized phase III clinical trial. J Clin Oncol 2008;26:22852291.
52. Motzer RJ, Bander NH, Nanus DM. Renal-cell carcinoma. N Engl J Med 1996;335:865-875.

53. Choueiri TK, Plantade A, Elson P, et al. Efficacy of sunitinib and sorafenib in metastatic papillary and chromophobe renal cell carcinoma. J Clin Oncol 2008;26:127-131.

54. Stadler WM, Figlin R, Ernstoff MS, et al. The Advanced Renal Cell Carcinoma Sorafenib (ARCCS) expanded access trial: safety and efficacy in patients (pts) with non-clear cell (NCC) renal cell carcinoma (RCC) [abstract]. J Clin Oncol 2007;25(Suppl 1: Abstract 5036.

55. Dutcher J, Szczylik C, Tannir N, et al. Correlation of survival with tumor histology, age, and prognostic risk group for previously untreated patients with advanced renal cell carcinoma ( $\mathrm{adv}$ RCC) receiving temsirolimus (TEMSR) or interferon-alpha (IFN) [abstract]. J Clin Oncol 2007;25(Suppl 1):Abstract 5033.

56. Schmidt L, Duh FM, Chen F, et al. Germline and somatic mutations in the tyrosine kinase domain of the MET proto-oncogene in papillary renal carcinomas. Nat Genet 1997;16:68-73.

57. Schmidt L, Junker K, Nakaigawa N, et al. Novel mutations of the MET proto-oncogene in papillary renal carcinomas. Oncogene 1999;18:2343-2350.

58. Kuroda N, Toi M, Hiroi M, Enzan H. Review of sarcomatoid renal cell carcinoma with focus on clinical and pathobiological aspects. Histol Histopathol 2003;18:551-555.

59. Cheville JC, Lohse CM, Zincke H, et al. Comparisons of outcome and prognostic features among histologic subtypes of renal cell carcinoma. Am J Surg Pathol 2003;27:612-624.

60. de Peralta-Venturina M, Moch H, Amin M, et al. Sarcomatoid differentiation in renal cell carcinoma: a study of 101 cases. Am J Surg Pathol 2001;25:275-284.

61. Mian BM, Bhadkamkar N, Slaton JW, et al. Prognostic factors and survival of patients with sarcomatoid renal cell carcinoma. J Urol 2002;167:65-70.

62. Golshayan AR, George S, Heng DY, et al. Metastatic sarcomatoid renal cell carcinoma treated with vascular endothelial growth factor-targeted therapy. J Clin Oncol 2009;27:235-241.

63. Culine S, Bekradda M, Terrier-Lacombe MJ, Droz JP. Treatment of sarcomatoid renal cell carcinoma: is there a role for chemotherapy? Eur Urol 1995;27:138-141.

64. Nanus DM, Garino A, Milowsky MI, et al. Active chemotherapy for sarcomatoid and rapidly progressing renal cell carcinoma. Cancer 2004;101:1545-1551.

65. Sella A, Logothetis CJ, Ro JY, et al. Sarcomatoid renal cell carcinoma. A treatable entity. Cancer 1987;60:1313-1318. 